\title{
A “Routine” Electrocardiogram
}

Michael A. Chen, MD, PhD

Department of Medicine, Harborview Medical Center, University of Washington School of Medicine, Seattle, Washington.

\section{Patient Presentation}

A 52-year-old woman with cirrhosis presented with a largevolume upper gastrointestinal (GI) bleed. After receiving massive volume and blood product resuscitation (18 U packed red blood cells [PRBCs], $17 \mathrm{U}$ fresh frozen plasma [FFP], 2 U cryoprecipitate, $1 \mathrm{U}$ platelets, and $14 \mathrm{~L}$ normal saline), a routine admission electrocardiogram (ECG) was obtained (Figure 1).

\section{Discussion}

The ECG shows normal sinus rhythm with a prolonged QT interval (specifically due to a long ST segment). The differential diagnosis of this pattern of QT prolongation includes hypocalcemia, long QT syndrome (variant 3), and hypothermia. Massive transfusion can result in the chelation of calcium by citrate resulting in hypocalcemia. This patient's serum calcium was $7 \mathrm{mg} / \mathrm{dL}$ (8.9-10.2) (ionized $0.21 \mathrm{mmol} / \mathrm{L}$; 1.18-1.38), her $\mathrm{pH}$ was 7.03. There were no overt signs or symptoms of hypocalcemia (paresthesias, twitching, tetany, or seizures.) and with aggressive replacement the calcium and the ECG normalized. Transfusions are an uncommon cause of hypocalcemia, with hypomagnesemia or hypermagnesemia, acute pancreatitis, rhabdomyolysis, tumor lysis syndrome, renal failure, vitamin D deficiency, pseudoparathyroidism and hypoparathyroidism being the more common disorders caused., ${ }^{1,2}$ This patient's magnesium was normal on admission ( $2.1 \mathrm{mg} / \mathrm{dL})$ and she did not have any of the other conditions mentioned. It is possible that hemodilution may also have played a role.

Genetic long QT syndrome (variant 3) can manifest with a similar ECG pattern, although the T-wave is sometimes peaked or biphasic in that condition. Our patient had no personal or family history of syncope or sudden death, and her ECG normalized with calcium replacement. ${ }^{3}$

Hypothermia can also present with a long QT interval secondary to a long ST segment. Our patient was normothermic, and had no other ECG findings suggestive of hypo-

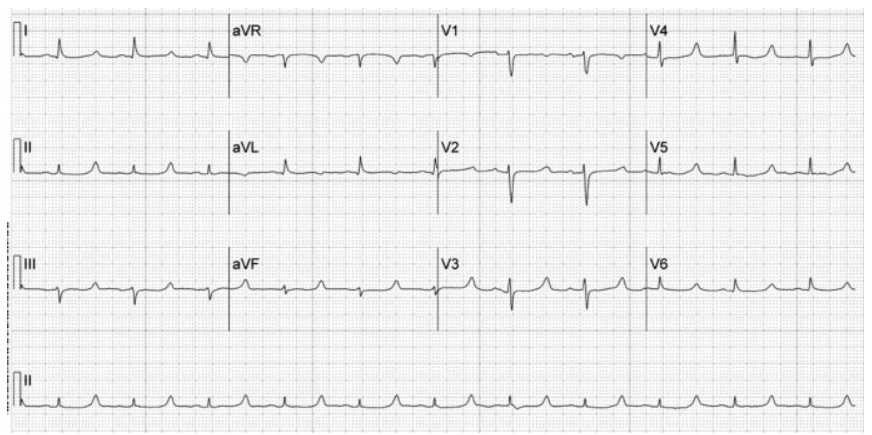

FIGURE 1. Admission electrocardiogram.

thermia (Osborn waves: notching of terminal portion of QRS), shivering artifacts, sinus bradycardia, atrial fibrillation, QRS prolongation, or prolongation of the PR interval. ${ }^{4}$

The differential diagnosis of a long QT interval with a long ST segment is short, and the clinical scenario will provide the etiology in most cases.

\section{Address for correspondence and reprint requests:}

Michael A. Chen, MD, PhD, Assistant Professor of Medicine (Cardiology), Harborview Medical Center, University of

Washington School of Medicine, 325 9th Avenue, Box 359748, Seattle, WA 98104; Telephone: 206-744-2289; Fax: 206-744-2224;

E-mail: michen@u.washington.edu Received 18 May 2008; revision received 1 August 2008; accepted 24 August 2008.

\section{References}

1. Khosla S. Hypercalcemia and hypocalcemia. In: Fauci AS, Braunwald E, Kasper DL, et al., eds. Harrison's Principles of Internal Medicine. Available at: http://www.accessmedicine.com/content.aspx?aID=2864354.

2. Rutledge R, Sheldon GF, Collins ML. Massive transfusion. Crit Care Clin. 1986;2:791-805.

3. Wehrens XH, Vos MA, Doevendans PA, Wellens HJ. Novel insights in the congenital long QT syndrome. Ann Intern Med. 2002;137:981-992.

4. Van Mieghem C, Sabbe M, Knockaert D. The clinical value of the ECG in noncardiac conditions. Chest. 2004;125:1561-1576. 